\title{
GEOGRAPHIC INFORMATION SYSTEMS AND SCIENCE: TODAY AND TOMORROW
}

\author{
Michael F. Goodchild ${ }^{1}$
}

\begin{abstract}
Great strides have been made in geographic information systems and science over the past 14 years, through the development of spatial data infrastructures and the infrastructure of data sharing; through advances in the technologies of positioning, data acquisition, data dissemination, and data analysis; and through advances in the science that lies behind the technology. Five future scenarios are examined: a world in which it is possible to know where everything is at all times; a world of positioning, representation, and wayfinding that is fully three-dimensional; a world that involves the citizen as both consumer and producer of geographic information; a world of ready access to predictions of future landscapes; and a world of real-time, dynamic information.
\end{abstract}

\section{INTRODUCTION}

In 1995 I wrote an article for the first issue of the new journal Geographic Information Sciences (Goodchild, 1995) in which I speculated on future directions for the field. 14 years later the journal is changing its name to the Annals of GIS, and it seems appropriate therefore to review that earlier paper, to examine the degree to which its speculations became reality, and to think about the years ahead. Of course prediction is notoriously risky, a striking example being the failure of the massive two-volume state-of-the-art review of GIS in 1991 (Maguire, Goodchild, and Rhind, 1991) to anticipate the enormous impact that the Web would have beginning in 1993.

The first part of this paper reviews the earlier survey and discusses its successes and failures. The second part looks at the state of the geographic information technologies in 2009, and the major discoveries that have been made to date in geographic information science. The third part of the paper looks at the future, presents a vision for the state of geographic information technologies five to ten years ahead, and describes the major challenges that remain in geographic information science.

\section{FOURTEEN YEARS OF DEVELOPMENT}

The term geographic information science (GIScience) was first defined in 1992 (Goodchild, 1992), and it was adopted in 1995 as the name of the new journal (substantially predating the renaming of the International Journal of Geographical Information Systems to the International Journal of Geographical Information Science).

\footnotetext{
${ }^{1}$ National Center for Geographic Information and Analysis, and Department of Geography, University of California, Santa Barbara, CA 93106-4060, USA. Phone +1 805893 8049, FAX +1 805893 3146, Email good@geog.ucsb.edu
} 
It is not surprising therefore that my 1995 paper began with a discussion of the term's meaning, and of the implications of its adoption by, for example, the newly formed U.S. University Consortium for Geographic Information Science. There was great excitement in 1995 about the potential of the new information-based economy and information industries, and GIScience seemed well positioned to benefit from it.

This was also the period of first excitement about the concept of spatial data infrastructure, following the definitive report of the U.S. National Research Council (NRC, 1993) and President Clinton’s Executive Order 12906 establishing the National Spatial Data Infrastructure (NSDI). It is clear now in hindsight that the GIScience community was remarkably ahead of the game in developing the components of NSDI: the metadata standards, geoportals, and search mechanisms that support widespread sharing of geographic information. Perhaps this was due to the particularly well-defined and bounded nature of geographic information compared to other types of information, and perhaps it was due to the proximity of a large and flourishing private sector and dedicated government agencies. Whatever the reason, it is clear that the community was many years ahead of other communities, such as the hydrologists or the ecologists, in the development of its data infrastructure.

The Open Geospatial Consortium (OGC) was just beginning its work in 1995, and since then it has grown into a highly effective mechanism for developing and encouraging the adoption of a series of important standards. Most notable among these are the Web standards WMS, WFS, WCS, and WPS, which today form the essential backbone of Web-based geographic information services. NSDI also anticipated the patchwork approach to geographic information production that is now so evident in the contributions being made by the general public through volunteered geographic information (VGI; Elwood, 2008). I ended the section with a comment on "the pressing need to extend (NSDI)'s principles to the international and global arenas”, a need that is now ably met by the work of the Global Spatial Data Infrastructure Association.

The second major section of my 1995 paper dealt with digital spatial data libraries, the difficulties traditional libraries face in sorting items by spatial and temporal frames, and the power of digital systems to enable such searches based on metadata - in effect, to answer the question "What have you got about there, (and possibly) then?" In 1994 the U.S. National Science Foundation had funded our Alexandria Digital Library project, one of the first to attempt to implement an on-line library of geographic information, or what was subsequently termed a geolibrary (Goodchild, 1998). At the time several technical difficulties were immediately apparent: How should one present the concept of scale, for example, to users who might have no understanding of basic cartographic principles? How should one enable users to specify location, when users might not be able to find an area of interest on a map, let alone specify its latitude and longitude? How should one deal with areas of interest that have no well-defined boundaries, such as "the Atlantic Ocean” or “downtown Santa Barbara”?

Today all of these issues have been addressed, in part by research in the academic GIScience community. The general public has become familiar with the concept of zoom, 
and with its expression in the user interfaces of sites such as Google Maps and MapQuest. The ability to recognize a placename or street address and to translate it to latitude/longitude is now routine, and scarcely worthy of mention. But some issues remain. Almost no progress has been made, for example, on the elusive problem of content-based search. It is still far from easy to search across large collections of satellite images for pictures containing a golf course, or a hurricane, and it is still necessary to rely on the annotations and tags that humans attach to pictures in repositories such as Flickr. Similarly, our geolibraries still function as collections of data sets, preserving the essential granularity of geographic information that was established when the information was acquired. The potential for search across a seamless database is still largely unfulfilled.

Both of these issues, of NSDI and the geolibrary, were at the top of my own research agenda in 1995. In the concluding section of the paper I noted the substantial progress that had been made in popularizing GIS across the various disciplines of the academy. Today, of course, that progress has continued to encompass large parts of the general public, at least on this side of the digital divide. Services such as Google Maps and Microsoft Virtual Earth have brought digital geographic information within reach of just about anyone, and have essentially democratized what for many years was viewed as the domain of highly trained experts. At the same time, much as been done to address the comment I made in that concluding section, at a time when students learned GIS via the command line, that "GIS is too difficult to use". The WIMP (windows, icons, menus, pointer) interface that took over GIS design in the late 1990s greatly reduced the pain students experienced in learning GIS, though it did not remove it entirely.

\section{GEOGRAPHIC INFORMATION SYSTEMS AND SCIENCE IN 2009}

\subsection{Systems}

The geographic information technologies of 2009 seem to fall into four more-or-less well-defined categories: systems for positioning, data acquisition, data dissemination, and analysis. The following section discusses each of these in turn, reviewing the state of the art and identifying areas where new developments can be expected in the near future.

\subsubsection{Positioning}

The Global Positioning System (GPS) and its Russian and European analogs has revolutionized the measurement of position on the Earth's surface, making it possible for the first time in human history to determine the position of an object quickly and cheaply (Kennedy, 2002). Versions of GPS can be embedded in mobile phones, wristwatches, and vehicles, and millions of densely sampled tracks are now being acquired every day in the interests of map-making, wildlife management, and the modeling of human spatial behavior. GPS has led to a new dynamism in the world of geographic information, which is for the first time able to monitor and analyze changes on the Earth's surface as they occur. Citizens are now able to monitor the progress of a flight, or the arrival of a bus, using simple devices to access Web sites that broadcast such information in real time. 
GPS remains a technology of the outdoors, however, as its signals are lost under dense tree cover, in buildings, and even in deep urban canyons. Route guidance systems, such as the familiar vehicle satnav, remain limited to locations where strong signals are available. Yet humans spend only a small fraction of their lives in such places, and we have as yet no reliable technology or data to support wayfinding within complex threedimensional structures such as retail complexes, subway stations, airports, or hospitals.

RFID (radio-frequency identification; Ahson and Ilyas, 2008) is rapidly becoming an important form of positioning technology, used to track the movement of goods from producer through retailer to consumer, to track pets and farm animals, and to manage building materials on construction sites. RFID may yet prove to be the best technology for indoor tracking, though many other possible solutions are being developed.

\subsubsection{Data acquisition}

Satellite and airborne remote sensing is now firmly established as a major source of geographic information (Jensen, 2007). Optical panchromatic sensors now image the Earth's surface at $50 \mathrm{~cm}$ resolution, while multispectral sensors add the potential for detailed differentiation of surface types. Research has shown that an enormous variety of variables and phenomena can be detected using different parts of the electromagnetic spectrum. Radar and microwave sources have been deployed to detect such variables as surface elevation and even to differentiate aspects of the subsurface under appropriate conditions, and LiDAR uses optical wavelengths to achieve remarkably detailed and precise knowledge of ground elevation and tree cover. Recently ground-based LiDAR has proven of great value in acquiring three-dimensional models of urban form.

However, perhaps the most significant development in geospatial data acquisition over the past few years has been the rapid emergence of user-generated content, a process by which users of the Internet are able to create and upload information. A variety of other terms describe this very recent phenomenon: Web 2.0, defined as a reversal of the initial top-down flow of Web information; and volunteered geographic information (VGI; Elwood, 2008), emphasizing the unpaid nature of the time its contributors spend on its creation. Typical contributors are citizens with little or no training or education in geography or cartography, and the activity is sometimes known collectively as neogeography (Turner, 2006) to distinguish it from the traditional activities of geographers.

Unlike the geographic information produced by mapping agencies and corporations, VGI carries no authority or guarantees of accuracy. It is impossible, of course, for any system of measurements, including measurements of phenomena on the Earth's surface, to be perfect (Zhang and Goodchild, 2002). Nevertheless evidence is accumulating that VGI can be every bit as accurate (http://povesham.wordpress.com/tag/osm/), mirroring the results of studies of other Web 2.0 sites such as Wikipedia (Giles, 2005). Neogeographers use GPS and mapping software to substitute for the skills that traditional geographers acquired, and that justified their claims to authority. But unlike traditional geographic 
information there are no formal mechanisms for testing the quality of VGI, or for reporting its quality in metadata. While traditional geographic information has documented reports of quality, assuring that inaccuracies are no more than allowed by published standards, VGI carries no such assurances. In short, both sources are inevitably inaccurate, but the inaccuracies of traditional geographic information are tested and well documented. Whether their magnitude is greater or less, however, is not as clear.

\subsubsection{Data dissemination}

The traditional media for dissemination of compiled geographic information - paper maps, globes, and atlases - were expensive to produce, cumbersome to ship and house, and difficult to catalog. Map libraries emerged as one solution to these issues, sequestering geographic information in specialized departments that developed their own systems of collection management. When aerial photography emerged as a new and rich source of geographic information, beginning in the early $20^{\text {th }}$ Century, it merely added to the existing problems of custodianship.

By the early 1990s, however, substantial portions of these collections had begun to migrate to digital media, first magnetic tape and later CDs and DVDs. The advent of the Web and the popularization of the Internet in the mid 1990s led almost immediately to a new interest in the use of electronic networks for dissemination and sharing. Geographic data warehouses and digital libraries were quickly established, and by the turn of the century a vast amount of data could be accessed using simple search and retrieval mechanisms. The term geolibrary was coined (Goodchild, 1998) to describe a digital collection of geographic data sets that is searchable using location as the primary key.

More recently the concept of a geoportal (Maguire and Longley, 2005) has emerged. These are single points of entry into a network of linked repositories, offering search across a unified catalog plus remote access to data sets that remain housed in their original collections. The Geospatial One-Stop (Goodchild, Fu, and Rich, 2007) is a successful example, linking hundreds of collections to thousands of users, and similar portals are sponsored by many national, state, and local governments and nongovernmental organizations.

In 2005 the appearance of virtual globes (Google Earth, Microsoft Virtual Earth, etc.) and Web mapping sites such as Google Maps added another dimension to the technology of geographic information dissemination. By providing a simple user interface and by publishing tools (application programming interfaces, scripting languages) these services quickly achieved a level of popular acceptance far beyond that previously typical of geographic information systems (Goodchild, 2008). Users were able to access data provided by third parties, displaying them in simple graphical overlays on the map base. Today hundreds of thousands of such mashups can be found on the Web, and the number is expanding constantly.

\subsubsection{Analysis}


The first efforts to build comprehensive computer applications for manipulating geographic information date from the mid 1960s. Today the term geographic information system (GIS) is widely accepted, and such systems are capable of a wide range of forms of manipulation and analysis (Longley et al., 2005). Some are targeted at particular application domains, such as transportation; some emphasize particular types of geographic information, such as remotely sensed images; and some are particularly adapted to the needs of dynamic simulation of Earth processes (http://pcraster.geo.uu.nl/).

Geographic information systems support a vast range of applications. In commerce, they are widely used to maintain inventories of distributed assets in the utility industry; to manage marketing efforts and to determine optimal locations for retail businesses and services; and to schedule delivery and pickup services. In science, they are particularly useful for examining patterns of phenomena on the Earth's surface, formulating and testing hypotheses about the spread of disease, the distribution of plant species and the behavior of animals, and the spatial organization of society. In government, they are used to make choices between alternative planning options and to manage social services. In the military, they are essential to battlefield control.

Many of the innovations in GIS of the past decade concern the user interface. The adoption of WIMP interfaces in the 1990s vastly improved the ease of use of GIS software, and greatly shortened the learning curve. Tools for exploratory spatial data analysis, such as GeoDa (http://geodacenter.asu.edu/), greatly enhanced the ability of GIS to examine data from multiple perspectives in the interests of hypothesis generation. New forms of representation based on the object-oriented model also brought GIS closer to how humans think about the world, and expanded our ability to represent both hierarchical relationships and dynamics. Issues remain, however, in the representation of the third spatial dimension, and in capturing phenomena that are fundamentally continuous over the Earth's surface, such as terrain, roads, and rivers.

\subsection{Science}

There are several ways of defining geographic information science (GIScience; Duckham, Goodchild, and Worboys, 2003), but all of them convey a similar message: there is more to GIS than rote pushing of buttons. GIScience is the science behind the systems, in other words the scientific knowledge on which GIS is based. That would include, for example, the various indexing schemes that have been discovered through research and implemented to improve the performance of GIS; or the algorithms that provide solutions to problems such as polygon overlay or the finding of a shortest path. GIScience can also be defined as the set of fundamental issues raised by the techology, or the critical issues that arise when the technology is employed. These would include accuracy and uncertainty, scale, and the methods used to capture the infinite complexity of the real world in binary digits.

Any science should be measured by its discoveries, and in GIScience there have been some very significant discoveries in the past 14 years. These include theories of representation, starting with the fundamental distinction between discrete-object and 
continuous-field conceptualizations. In essence this posits that there are two ways in which humans conceive of the geographic world around them: as a collection of discrete things littering an otherwise empty space, and as a collection of continuous variables. More recently object fields (Cova and Goodchild, 2002) and metamaps (Takeyama and Couclelis, 1997) have been added to the collection, and Goodchild, Yuan, and Cova (2007) have shown that all of these can be reduced to two unifying and fundamental concepts: geo-atoms and geo-dipoles.

Very substantial progress has been made in the understanding of uncertainty, or what the digital representations of the world leave out - the differences between a digital representation of the world in a GIS, and the real world itself (Zhang and Goodchild, 2002). An representation must approximate, generalize, or otherwise simplify what is in reality an infinitely complex world. Uncertainty includes issues of error and inaccuracy, and also encompasses all of the issues that arise when humans use vaguely defined terms to describe, classify, and in other ways simplify the world around them. We know much more than we did 14 years ago about the propagation of uncertainty through GIS analysis (Heuvelink, 1998), and we are beginning to develop rigorous methods for downscaling in other words, for introducing detail into coarsely scaled data - using the framework of geostatistics (Boucher, Kyriakidis, and Cronkite-Ratcliff, 2008).

Another area of important progress is in spatial cognition, in other words in the ways in which humans learn and think about the world around them. Understanding of such processes is critical if we are to improve the usability of GIS, by making it more closely resemble the ways humans themselves reason about the world. GIS is in many ways the interface between the informal, loose world of human cognition and discourse and the rigorous, formal, and precise world of digital computers. Should humans be required to adapt themselves to the machine, or can we find compromises that make it easier for machines to assist humans in their everyday lives as well as in scientific research?

Finally, significant progress has been made in the past 14 years in understanding more about the world we are trying to represent. The knowledge represented by Tobler's First Law of Geography (Tobler, 1970), for example, is essential if systems are to be designed to function effectively and efficiently. The law states that "nearby things are more similar than distant things", and this simple generalization ensures that we can confidently interpolate continuous surfaces from point observations, and express properties of areas as if they were uniform. At the same time it creates substantial difficulties in applying standard statistical methods and tests to geographic information. Anselin (1989) identified this property, generally known as spatial dependence, along with statistical non-stationarity or heterogeneity, as the two properties that more than any others "make spatial special”.

\section{LOOKING FORWARD}

Prophesying about the future is of course enormously dangerous, but nevertheless there seem to be several things one can predict with some confidence about the geographic information technologies of the future - if not 50 or even 20 years ahead, but perhaps 5 or 
10. In this section I speculate about five developments, each of which is on or only slightly over the current horizon.

\subsection{Knowing where everything is}

The positioning technologies discussed earlier - GPS and RFID - are already widely used, and suggest that we need to anticipate a world in which it will be possible to know where everything is, at all times. Clearly this does not mean that we will ever know the location of every molecule, but there are already substantial domains over which this kind of knowledge is at least partially available. For example, we already know where every mobile phone is, provided it is turned on and within range, and with the most recent phones we know location based on GPS to better than 10m. Extensive databases created by tracking large numbers of mobile phones have already been used in research projects, raising important issues of privacy. We know the locations of a significant fraction of the vehicle fleet based on GPS, particularly trucks, and we know when vehicles carrying RFID-based passes travel through toll gates. In some European countries every farm animal is RFID-tagged, as is a substantial fraction of the goods moving through large U.S. retail stores. Imagine, then, the value of knowing the location of every potential victim of a disaster, such as the Oklahoma City bombing of April 1995 or the Wenchuan earthquake of May 2008. Such knowledge would be immediately useful in the search and rescue effort, provided sufficient assurances could be made to guarantee privacy. Similar comments might be made about knowing the real-time locations of rescue teams, or personnel and materiel in a military context.

\subsection{The third spatial dimension}

Comments have already been made about the two-dimensional, outdoor nature of our current geographic data and tools. Great progress has been made in recent years in automating the process of acquiring three-dimensional data. Specially equipped vans, for example, can now be driven along city streets continuously capturing not only photographs but also three-dimensional structures using ground-based LiDAR. Detailed digital models have been constructed for many of the world's large cities, and made available through sites such as Microsoft Virtual Earth. The technology to capture the internal 3D structure of buildings is much less advanced, however, despite the importance of such information in building management, wayfinding, and warfare.

One solution to this problem is to make use of the digital models that are now a universal part of the architectural design process. The field of building information management (BIM) has adopted a series of standards, and these have been effectively interfaced with GIS through projects such as CityGML (http://www.citygml.org/). BIM can be very rich, but is unfortunately available for only recently constructed buildings.

Research is still needed on the appropriate ways to represent three-dimensional structures - in effect, building ontology - in order to satisfy the various applications of threedimensional representations. Many approaches make assumptions, such as vertical walls and right-angle corners, that are valid only for certain cultures. Modeling the movement 
of individuals during a building evacuation, one obvious and important application, requires a form of representation, analogous to the link/node structure of road-network representations, that may be very different from the representations required by other applications such as the work of architects or the construction industry.

At this point also there is also no consensus on the best technology for determining position in complex 3D structures. Experimental technologies are available based on WiFi beacons, local extensions of GPS, ultrasound, and lasers, but none has yet emerged as the dominant approach or the basis for standards. Nevertheless one can be confident that substantial progress will be made in this area in the next few years.

\subsection{The role of the citizen}

Section 3.1.2 has already identified the citizen as an important and rapidly growing source of geographic data, and Section 3.1.3 has discussed the success of virtual globes and other Web-based mechanisms for improving the role of the citizen as a consumer of geographic information. In future, then, it seems that the citizen will play an increasing role as both consumer and producer - a concept that is often termed the GeoWeb (Scharl and Tochtermann, 2007).

A growing research literature is devoted to this phenomenon (see, for example, Elwood, 2008). One key issue is whether there are limits, particularly in terms of themes.

Substantial resources have already accumulated through voluntary efforts in describing places (e.g., Wikimapia) and in building street databases (OpenStreetMap). But are these themes particularly suited to voluntary effort, and are there themes that are so advanced that citizens will likely never make substantive contributions? Goodchild (in press) discusses this issue, and concludes that the themes that appear most problematic are the result of prior conditions and constraints, particularly economies of scale. He concludes that if themes are rethought based on well-defined use cases then there appear to be no effective limits to what citizens can contribute, with sufficient guidance and appropriate protocols. Moreover citizens possess one important advantage over experts: knowledge of, and access to, local ground truth.

Two specific areas seem to present an especially compelling case for citizen participation in geographic information production. First, recent disasters in areas well endowed with technology, such as recent wildfires in California, have clearly demonstrated the value of citizen participation in providing early warning and early damage reports. Despite the risk of error or deliberate malfeasance, these mechanisms have the enormous advantage of speed. Second, day-to-day familiarity with the local area makes the citizen a valuable source of information about changes, in street patterns for example. Such information is of great value to the producers of street databases, and many have already organized networks of citizens with appropriate equipment, such as GPS vehicle tracking devices.

\subsection{Access to geographic information}


As noted earlier, the virtual globes and other Web mapping services have brought the power of digital geographic information directly to the citizen in unprecedented ways. Almost all of this information, however, concerns how the world currently looks. In principle one could use similar mechanisms to keep the public information about how the world will look, or perhaps more correctly might look, in the future. Virtual globes would be a very powerful way of sharing informed about future scenarios, at both global and local scales. The impacts of community planning decisions, global economic recession, new diseases, or global environmental change could all be visualized through a single, easy-to-use portal, providing a direct connection between the predictive work of scientists, the decisions of public officials, and the general public.

Several technical issues stand in the way. All predictions are necessarily uncertain, so it would be necessary to provide clear and unmistakable visualizations of doubt, something that is still difficult even in the sophisticated environment of a GIS. There is uncertainty about whether the average citizen is capable of treating such information responsibly, and research is needed to address the question of how such information should be presented, and to whom. Virtual globes operate today on a strictly visual basis, providing information in a form that is as close as possible to actual appearance, yet prediction would require an ability to visualize phenomena that are inherently abstract.

\subsection{A technology of dynamics}

It has often been said that public policy is driven by change - that a technology that emphasizes how the world looks today will never capture the imagination as much as one that shows how the world is changing, or is likely to change in the future. Great strides have been made in recent years in addressing the dynamic aspects of geographic information, and today an abundance of sources are providing real-time, dynamic information about various aspects of the Earth's surface. Live feeds of weather, traffic congestion, and the locations of public transit vehicles are already familiar to many Web users. Together, they are creating a world of geographic information that is very different from the static, map-based world of the past.

In the future, I think we have to imagine the possibility of a world of real-time geographic information. Even today it is technically possible to imagine knowing the complete, real-time state of the transportation system of a city, for example, including the locations and speeds of all vehicles, and the state of all roads and public transit routes. Similarly we should imagine a future that is fully informed about the state of human health, including the real-time progress of disease outbreaks.

These possibilities rely on the growth of networks of sensors, at fixed points in the environment, or carried on vehicles and pedestrians. In addition humans will act as intelligent sensors of various properties of their environment (Goodchild, 2007), particularly the more subtle and abstract properties that require human perception and intelligence, such as the sense of crowding or the sense of threat to one's person.

\section{CONCLUSION}


14 years ago I concluded that GIS had made enormous progress over the preceding few years, and that it was by then accepted in a wide range of disciplines. Today we have moved far beyond that point, to where geospatial data and tools are familiar to virtually everyone on the well-endowed side of the digital divide. Yet the ability to use these powerful tools effectively, and to avoid obvious mistakes, remains limited to a minority of what are sometimes called spatially aware professionals. At the same time GIS has become easier to use, and the fly-by that once required the advanced skills of a GIS professional can now be generated by a child of ten. This has shifted the educational agenda, and the primary question is no longer "How to train a GIS professional to use ArcGIS?” but instead "In the world of Google Maps, what does everyone need to know?" The answer lies in the world of GIScience, and in the issues of representation and data modeling, uncertainty, scale, and visualization that continue to drive the research agenda.

That research agenda remains as rich as ever. While we have made great progress over the past two decades, as Section 3.2 showed, there is a large set of important problems that must be solved by research if the next generation of geospatial technology is to succeed. It includes issues of scaling, in dealing with exponentially increasing numbers of data sources and users. It includes the issues raised in Section 4 that must be addressed in anticipation of future technology. The world of VGI would have been almost inconceivable 14 years ago, as would the world of virtual globes, and many of their impacts were wholly unanticipated. Issues of conflation are now in the forefront as we begin to address the issues raised by an abundance of potentially duplicative information.

Like the discipline of geography, GIS often becomes the technological glue that holds together the large groups of collaborators that seem to be required to solve many of the complex problems of today. I ended the paper 14 years ago with the comment that "The information sciences like GIScience can flourish along with this new way of doing science, as the ability to handle, store, describe, exchange, and organize information becomes increasingly the key to solving our most pressing problems." 14 years have produced very substantial progress on problems of interoperability, and shared ontologies now exist in many domains. The comment remains true nevertheless, and today it would be almost inconceivable that a research proposal would not pay attention to computational infrastructure. When the research concerns the surface or near-surface of the Earth, that infrastructure must of necessity be grounded in GIScience.

\section{REFERENCES}

Anselin, L., 1989. What is special about spatial data? Alternative perspectives on spatial data analysis. Technical Report 89-4. Santa Barbara: National Center for Geographic Information and Analysis.

Ayson, S. and M. Ilyas, editors, 2008. RFID Handbook: Applications, Technology, Security, and Privacy. Boca Raton: CRC Press. 
Boucher, A., P.C. Kyriakidis, and C. Cronkite-Ratcliff, 2008. Geostatistical solutions for super-resolution land cover mapping. IEEE Transactions on Geoscience and Remote Sensing 46(1): 272-283.

Cova, T.J. and M.F. Goodchild, 2002. Extending geographical representation to include fields of spatial objects. International Journal of Geographical Information Science 16(6): 509-532.

Duckham, M., M.F. Goodchild, and M.F. Worboys, editors, 2003. Foundations of Geographic Information Science. New York: Taylor and Francis.

Elwood, S., 2008. Volunteered geographic information: key questions, concepts and methods to guide emerging research and practice. GeoJournal 72(3-4): 133-135.

Giles, J., 2005. Special Report: Internet encyclopedias go head to head. Nature 438: 900901.

Goodchild, M.F., 1998. The geolibrary. In S. Carver, editor, Innovations in GIS 5. London: Taylor and Francis, pp. 59-68.

Goodchild, M.F., 2007. Citizens as sensors: the world of volunteered geography. GeoJournal 69(4): 211-221.

Goodchild, M.F., 2008. The use cases of digital earth. International Journal of Digital Earth 1(1): 31-42.

Goodchild, M.F., in press. Neogeography and the nature of geographic expertise. Journal of Location Based Services.

Goodchild, M.F., P. Fu, and P. Rich, 2007. Sharing geographic information: an assessment of the Geospatial One-Stop. Annals of the Association of American Geographers 97(2): 249-265.

Goodchild, M.F., M. Yuan, and T.J. Cova, 2007. Towards a general theory of geographic representation in GIS. International Journal of Geographical Information Science 21(3): 239-260.

Heuvelink, G.B.M., 1998. Error Propagation in Environmental Modeling with GIS. London: Taylor and Francis.

Jensen, J.R, 2007. Remote Sensing of the Environment: An Earth Resource Perspective. Second Edition. Upper Saddle River, NJ: Prentice Hall.

Kennedy, M., 2002. The Global Positioning System and GIS: An Introduction. New York: Taylor and Francis.

Longley, P.A., M.F. Goodchild, D.J. Maguire, and D.W. Rhind, 2005. Geographic Information Systems and Science. Second Edition. New York: Wiley.

Maguire, D.J. and P.A. Longley, 2005. The emergence of geoportals and their role in spatial data infrastructures. Computers, Environment and Urban Systems 29(1): 3-14.

National Research Council, 1993. Toward a Coordinated Spatial Data Infrastructure for the Nation. Washington, DC: National Academies Press.

Scharl, A. and K. Tochtermann, editors, 2007. The Geospatial Web: How Geobrowsers, Social Software and the Web 2.0 Are Shaping the Network Society. London: Springer.

Takeyama, M. and H. Couclelis, 1997. Map dynamics: integrating cellular automata and GIS through Geo-Algebra. International Journal of Geographical Information Science 11: 73-91. 
Tobler, W.R., 1970. A computer movie simulating urban growth in the Detroit region. Economic Geography 46(2): 234-240.

Turner, A., 2006. Introduction to Neogeography. Sebastopol, CA: O’Reilly.

Zhang, J.-X. and M.F. Goodchild, 2002. Uncertainty in Geographical Information. New York: Taylor and Francis. 